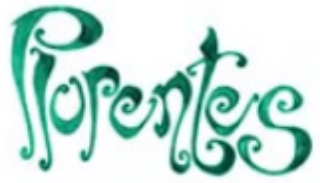

Artes y Letras
Plurentes. Artes y Letras

ISSN: 1853-6212

plurentesunlp@gmail.com

Universidad Nacional de La Plata

Secretaría de Asuntos Académicos

Prosecretaría de Asuntos Académicos

Bachillerato de Bellas Artes, "Prof. Francisco A. De Santo" Argentina

\title{
La música y sus modos de articulación en la narración cinematográfica
}

Loudet, Pablo; Compagnet, Leonel

La música y sus modos de articulación en la narración cinematográfica

Plurentes. Artes y Letras, núm. 11, e004, 2020

Universidad Nacional de La Plata

Secretaría de Asuntos Académicos

Prosecretaría de Asuntos Académicos

Bachillerato de Bellas Artes, "Prof. Francisco A. De Santo"

Argentina

DOI: https://doi.org/10.24215/18536212e004

Atribución no comercial compartir igual (CC BY-NC-SA) 4.0 


\section{La música y sus modos de articulación en la narración cinematográfica}

Music ant its modes of articulation in cinematographic storytelling

Pablo Loudet

Bachillerato de Bellas Artes "Prof. Francisco A. De Santo",

DOI: https://doi.org/10.24215/18536212e004

Universidad Nacional de La Plata, Argentina, Argentina

ploudet@gmail.com

Leonel Compagnet

Bachillerato de Bellas Artes "Prof. Francisco A. De Santo"

Universidad Nacional de La Plata, Argentina

leonelcompagnet@gmail.com

Recepción: 13 Septiembre 2020

Aprobación: 18 Septiembre 2020

Publicación: 26 Octubre 2020

\section{ReSUMEN:}

Este artículo se desprende del informe final del Proyecto de Investigación La música y sus formas de articulación en la narración cinematográfica, desarrollado en el Bachillerato de Bellas Artes (UNLP). Trata sobre los modos en que la música se incorpora a una obra integral de arte cinematográfico. El cine ha hecho una permanente utilización de la música y en ese ámbito, ella ha desarrollado formas de uso, recursos y criterios que la identifican. Cine y música, han generado vínculos de coherencia, colaboración, solidaridad y complementariedad, que es necesario investigar para arribar a un conocimiento profundo de los mismos.

Palabras Clave: Música, Cine, Narración, Función, Articulación.

\section{ABstract:}

This article is apparent from the final report of the Research Project "Music and its forms of articulation in film storytelling" developed at the Bachillerato de Bellas (UNLP). It's about the ways in which music is incorporated into a comprehensive work of cinematic art. Cinema has made a permanent use of music and in this field, it has developed forms of use, resources and criteria that identify it. Cinema and music have generated links of coherence, collaboration, solidarity and complementarity, which need to be investigated in order to achieve an in-depth knowledge of them.

KEYWORDS: Music, Cinema, Narration, Function, Articulation.

El cine es un tipo de disciplina artística de gran potencia expresiva. Su evolución a través de todo el siglo XX y su estado actual así lo demuestran. El cine surge a fines del siglo XIX y la música lo ha acompañado permanentemente desde los orígenes hasta la actualidad. Se ha dado de esta manera, como consecuencia de una necesidad: es que el cine en sí mismo, es un arte incompleto y necesita de otros medios para expresarse, y sin dudas la música es uno de esos recursos más utilizados.

La música de cine, entendida como toda música compuesta o recopilada para estar incorporada o integrada a películas, está definida por su función y no por su forma. Los elementos que la definen son más bien "extramusicales" y por lo tanto no ponen limitaciones con respecto al estilo, la forma, el género, el lenguaje, etc.

Las funciones de la música de cine podrían ser agrupadas en las siguientes categorías: ambientadora, expresiva, estructural y narrativa.

La función ambientadora es la que está vinculada a aspectos estéticos. La música informa al espectador acerca de las "coordenadas" de la película, lo pone en situación. Se da en dos niveles: ambientación contextual con la cual la música informa del tiempo y el espacio de lo narrado: momentos históricos, lugares geográficos, 
niveles sociales, etc.; y ambientación de género con la cual la música informa respecto de los géneros cinematográficos (comedia, drama, terror, suspenso, etc.) o da el “tono" general de la narración.

La función expresiva está vinculada a aspectos expresivos. La música contribuye a generar en la narración determinadas emociones, sentimientos y sensaciones tales como tristeza, alegría, tensión, angustia, miedo, terror, alegría, nostalgia, heroicidad, etc.

La función estructural, está vinculada a la forma del relato. La música sirve de apoyo a la organización estructural de la película o a la forma de la narración. Contribuye a enlazar o articular planos, escenas y secuencias de manera sincrónica o asincrónica. También puede contribuir a anticipar, retardar, acelerar, ralentizar, marcar ritmos narrativos, dar continuidad y equilibrio estructural, sustituir fragmentos, etc.

La función narrativa es la que está vinculada al contenido. La música contribuye a la efectividad narrativa, a la acción dramática; da información sobre la propia historia contada y sobre su interpretación. Ayuda a profundizar, ampliar, complementar, alterar e incluso contradecir aquello que esté explícito o sugerido en el guión.

Partiendo de estas funciones, que de alguna manera definen el "para qué" existe la música en la película, y cuál es su utilidad, podríamos profundizar el análisis e ingresar en el terreno del “cómo” está incorporada la música en el filme y para ello debiéramos definir el modo o la manera en que la música se articula en la narración cinematográfica.

Los modos de incorporación de la música en la narración cinematográfica son numerosos siguiendo distintos criterios. De acuerdo al rol que ocupa en la película puede ser principal o secundaria; de acuerdo a su plano auditivo puede estar en primer plano, plano medio, plano de fondo, etc.; según su ubicación en el montaje puede ser música inicial de títulos o música final; de acuerdo a la sintaxis puede ser música articuladora o enlazadora, sincrónica o asincrónica con la imagen, etc. Pero este trabajo se concentra exclusivamente en el modo en que la música se articula con la narración respecto del contenido de la historia contada, del relato mismo. En base a ello se propone una clasificación general con distintas subcategorías, su correspondiente definición conceptual y su ejemplificación con la descripción y análisis de diversos fragmentos cinematográficos.

\section{1) DIEGESIS \\ LA MUSICA Y SU MODO DE ARTICULACION RESPECTO \\ 2) SEMANTICIDAD \\ DEL CONTENIDO \\ 3) RECURSOS NARRATIVOS \\ 1) LA MÚSICA Y SUS MODOS DE ARTICULACIÓN EN LA NARRACIÓN CINEMATOGRÁFICA RESPECTO DE LA DIÉGESIS}

La palabra diégesis es de origen griego y podría traducirse como relato o narración. Se refiere al mundo (ficticio) en el que ocurren las situaciones y acontecimientos narrados. En otras palabras, diegético es todo aquello que forma parte de la historia narrada y no de la narración en sí. Si este concepto lo aplicamos a la música, tenemos: 


\author{
a) MUSICA DIEGETICA \\ DIEGESIS $\quad$ b) MUSICA INCIDENTAL \\ c) ALTERNANCIA ENTRE MUSICA INCIDENTAL Y DIEGETICA
}

\title{
A) Música diegética
}

Es la música que forma parte de la historia misma narrada y está incluida en ella. Por lo tanto, es escuchada por los personajes de dicha narración. Es interna a la historia narrada y en consecuencia tiene un carácter de realidad. Antiguamente se consideraba música diegética a aquella cuya fuente sonora aparecía en pantalla, y por lo tanto provenía de un lugar ópticamente real (un aparato de radio, una orquesta, un cantante, un tocadiscos, etc.) y el sonido era sincrónico con la fuente. Pero con la evolución del lenguaje musical del cine, existen nuevas situaciones en las cuales cierta música es considerada diegética, y no necesariamente aparece la fuente en pantalla o en el dispositivo que se ve (una computadora, un teléfono móvil, música ambiental de lugar público)

Ensayo de orquesta (1978). Dirección de Federico Fellini; música de Nino Rota

En una de las escenas del filme, se aprecia a un conjunto de músicos, tocando en vivo, ensayando bajo la batuta del director. Se escucha un tema musical rítmico, pulsante, de carácter alegre. La instrumentación es cargada, sonando el tutti orquestal en varios momentos. Es repetitivo, obsesivo, bufonesco y grotesco. Hay momentos de continuidad musical alternada con las habituales interrupciones, indicaciones y repeticiones que se dan en un ensayo.

El estilo musical del fragmento es un clásico ejemplo de las bandas sonoras compuestas por Nino Rota para los filmes de Fellini, hechas en muchos casos con estructuras repetitivas y un espíritu circense, sin dejar de lado el carácter emocional, nostálgico y melancólico. Este tipo de música ha sido recurrente a lo largo de su carrera, y podemos reconocer una película del director por su música. Podemos apreciar cómo se utiliza la música como excusa para construir las convenciones de su imagen en torno a lo payasesco, una pintura de esos personajes caricaturescos que con esfuerzo trabajan al mando del director de orquesta.

Desde el contenido se establece un campo de tensiones a partir de la alternancia del plano fijo y el plano en movimiento, transformando a los personajes en figurines cómicos que pasan a formar parte del universo musical propuesto por el compositor. Hay en la escena un momento a tener en cuenta. Muchos de los personajes que tocan sus instrumentos musicales se sacan las ropas agotados de ensayar incesantemente, pero los demás siguen tocando sin detener la música. Inmediatamente, ya sin algunas de sus ropas vuelven a incorporarse a la ejecución orquestal. Este precepto es muy fellinesco: "el show debe continuar", el arte entra a tener sus campos de tensión con el trabajador. Este es otro de los universos propuestos en la obra de Federico Fellini. Podemos apreciar como las decisiones del director edifican el proceso de estilización, en la comicidad de la escena para rubricarla con su estilo. Las decisiones dramáticas se integran a la diégesis musical, con ese valor agregado que nos lleva a la reflexión del contenido. 


\section{B) Música incidental (o extradiegética)}

Se trata de aquella música que no forma parte de la narración misma y por lo tanto es "irreal" y de carácter abstracto. Además, es externa a la historia, en off y es solo escuchada por los espectadores, pero no por los personajes del filme. A pesar de esa "irrealidad" respecto de la historia narrada, la presencia de ella es un convencionalismo que es aceptado. Cabe destacar que este tipo de música es también la más usada en la historia del cine.

Papillón (1973). Dirección de Franklin Schaffner; música de Jerry Goldsmith

En el final de la cinta, se hace audible el tema musical principal de la película. Se repite varias veces, aunque cambiando su instrumentación, carácter y tempo adaptándose a las necesidades de la narración. Es un tema breve, en modo menor, casi siempre con carácter nostálgico y melancólico.

La escena podemos dividirla en tres momentos del análisis en torno al carácter musical y la puesta en escena. No perdamos de vista que es la despedida de los personajes, Papillón y Dega, luego de permanecer toda una vida encarcelados en una prisión en la Guyana Francesa.

Las posibilidades de fuga son prácticamente nulas: por un lado, la ancianidad de los personajes y por el otro, la peligrosidad del mar que rodea la isla. Esto es importante para entender el carácter musical en torno a lo incidental. El valor romántico de la escena estará dado por el contexto descripto anteriormente.

El primer momento es la irrupción musical cuando Papillón se abraza con Dega como el último acto de despedida. Podríamos decir que este momento en torno a lo emocional pertenece a ambos personajes, y señala el vínculo amistoso entre ambos. Es un condicionante visual. Se puede ver una construcción clásica en el valor del encuadre y en el sentido del montaje. La acción dramática señala el vínculo y las emociones del suceso en cuestión. En la música, suena el tema principal con carácter tranquilo y melancólico con la melodía tocada por el oboe.

En el segundo momento, podemos apreciar cómo, en el plano general que los enmarca, ambos personajes se separan. Papillón arroja un rudimentario equipaje con el que flotará posteriormente en su escape por el mar. En ese punto la instrumentación y la intensidad de la música comienza a crecer, direccionándose a un clímax sonoro, para construir la gravedad del espacio venidero y la acción épica que emprenderá el protagonista. Inmediatamente, hay un corte en el montaje que muestra una imagen más general donde podemos apreciar la altura del acantilado. La música nos cuenta el espacio, pero también la acción. Papillón salta hacia el mar, el movimiento es ralentizado por la cámara y subrayado por un extenso y fortísimo trémolo de platillo: es el salto hacia la libertad. Luego de la caída, todo queda en silencio.

El tercer momento de esta estructura, se inicia con un silencio donde se alternarán planos de los dos personajes a la distancia. Allí, el único sonido tiene que ver con las olas. La música irrumpe con la sonrisa de Dega que queda parado en el acantilado. Lo que se escucha es nuevamente el tema con la melodía en el acordeón. Tanto la interpretación actoral, como el carácter musical, tienen que ver con una mezcla entre nostalgia y alegría por lo que ha logrado el personaje. Esto nos indica algo del sueño conjunto de fugarse más allá de la decisión de este último de no hacerlo. Claro está que esta decisión tiene que ver con la construcción del carácter de cada uno de ellos. La acción dramática que define ese momento musical, es la salida de cuadro del personaje, y así volver con el que escapa. Ya con Papillón en altamar, el tema musical vuelve a repetirse con mayor instrumentación y más animado. Los personajes se están separando, pero la música los sigue uniendo emocionalmente. La secuencia avanza y el tema se repite una vez más, con una instrumentación creciente en donde el protagonismo melódico lo toman las maderas. Ya en el final de la frase musical se escuchan unas palabras de Papillón, que sirven como nexo sonoro a lo que sigue: "Ustedes bastardos, quédense aqui'". Inmediatamente vuelve a aparecer el tema ya en tutti orquestal y a un ritmo marcado en tiempo de vals, simulando acompañar el ritmo de las olas: una decisión acertada del compositor Jerry Goldsmith, ya que en la trama del filme, el movimiento del oleaje había sido "descubierto" por Papillón y sería lo que le permitiría alejarse de la isla hacia libertad. La música refuerza y subraya el significado del movimiento del mar. 
En todo el fragmento, la música es claramente incidental. Sería imposible que una orquesta toque en el medio del océano. Pero más allá de esta obviedad se percibe claramente que la narración está construida con una música direccionada hacia los espectadores y de esta manera lograr una empatía con la emoción de los personajes: el sueño de libertad de ambos.

\section{C) Alternancia entre música diegética e incidental}

En este caso el compositor hace un juego entre los dos tipos de música buscando un efecto estético en el espectador.

Kill Bill (2003). Dirección de Quentin Tarantino; música de Bernard Herrmann

En un momento del filme, uno de los personajes femeninos, ingresa a un hospital y la melodía que la acompaña es una cita de la música de otra película: Nervios rotos (1968) de Roy Boulting con música de Bernard Herrmann Este recurso de emplear música preexistente adaptada de otros filmes es muy usado por parte de Tarantino. Se puede apreciar una dialéctica entre música e imagen en torno al componente estético: el sentido de la alternancia y el valor cambiante y transformador pensados como células independientes que se interrelacionan para constituir el todo. En este ejemplo también asistiremos a una propuesta de subjetivación.

Como dijimos, la escena inicia con un personaje que hará las veces de victimaria, Elle, ingresando a un hospital, y aparentemente está silbando. Inmediatamente asociamos la melodía que se escucha al campo de lo diegético. Si bien en un primer momento, la cámara toma al personaje de espaldas (y por lo tanto no se ve su rostro), el silbido se identifica inmediatamente con ella porque el sonido está localizado y focalizado. Luego cuando la cámara la enfoca de frente se confirma que la música es diegética porque se ve el gesto del silbido en los labios del personaje.

Un travelling acompaña a Elle a lo largo del pasillo, hasta que entra en una habitación yéndose de cuadro. La cámara sigue por el pasillo rompiendo el clasicismo de acompañar al personaje, y desprendiéndose para darnos la posibilidad de seguirla como un ente en el camino hasta el objetivo final. Todo será acompañado con el silbido que hasta ese momento era música diegética para empezar a convertirse en incidental, incluyendo una extensa reverberación y un acompañamiento musical extradiegético. El uso de la reverberación produce un cambio en la percepción respecto del espacio: el sonido ya no está focalizado, sino que más bien es envolvente y amplio. Esta operación comienza a significar la peligrosidad de lo que vendrá y sugiere un "vector" entre víctima y victimario: Elle funciona como ente fantasmal, a partir del silbido que sobrevuela el espacio.

El otro personaje, la víctima, Beatrix, en su indefensión producto de su imposibilidad motriz, se define desde su materialidad morfológica. El director presenta el suceso y lo define con un encuadre cerrado del personaje tirado en la cama sumado al silbido incidental desde un fuera de campo del victimario. Esta operación habilita para comenzar a construir un "mientras tanto" con gran destreza narrativa. El director comienza a jugar con la pantalla partida para potenciar ese paralelismo y su valor cambiante. Por un lado, la víctima, trabajando los planos detalles de su quietud. Por el otro, los planos detalles en los preparativos de cada elemento letal. Paralelamente el tema musical transcurre y va deformándose representando la maldad de Elle. Una maldad que ya ha inundado todo el espacio haciéndose omnipresente. Paradójicamente no tiene un carácter que despierte terror sino más bien se mantiene amable y pegadizo, aunque con presencia de disonancias armónicas cada vez más notables.

Elle, una vez preparada, dará lugar al director para hacer desaparecer la pantalla partida y así volver al pasillo, transformada en una enfermera. Esta vez se seguirá a ese personaje hasta vincularla al objetivo de llegar a su víctima, tal como lo hiciera previamente la cámara, de forma independiente. Los elementos constitutivos de la puesta en escena son expositivamente claros. Funcionan y se alternan con gran precisión para edificar la imagen.

A esta altura, la música suena totalmente transformada, fortísima, disonante con el tutti orquestal, melodía en cuerdas graves y trinos en instrumentos de vientos en el registro sobre agudo. El carácter es tenebroso y 
caótico. La protagonista ya no silba. Esto confirma que la música ha dejado de ser diegética, para convertirse decididamente en incidental. Narrativamente Elle ya no necesita silbar, porque la maldad ha sido liberada.

\section{2) LA MÚSICA Y SU FORMA DE ARTICULACIÓN EN LA NARRACIÓN CINEMATOGRÁFICA RESPECTO DE LA SEMANTICIDAD}

Esta categoría refiere a la manera en que el discurso musical interactúa con el significado o el sentido del discurso visual, proponiendo identificar mensajes coincidentes en relación con distintos elementos. Dicho de otra forma, si existen coincidencias entre los discursos sonoros y visuales, a partir de ciertos paralelismos que podrían establecerse. De esta manera la música sería empática respecto de la imagen. Por otro lado, el compositor puede jugar con este recurso de un modo opuesto e intentar equilibrar ciertas situaciones otorgándole a la música un carácter o significado contrario al que lleva la imagen, generando disidencia en vez de coincidencia. La utilización de este recurso generalmente busca producir situaciones de ironía, reflexión o incertidumbre e incluso narrarnos algo que no es explícito y que la música nos cuenta de manera subyacente y que pueden expresar resultados estéticos interesantes. En este otro caso la música sería anempática.

De acuerdo a esto podrían establecerse coincidencias o disidencias de distinto tipo:

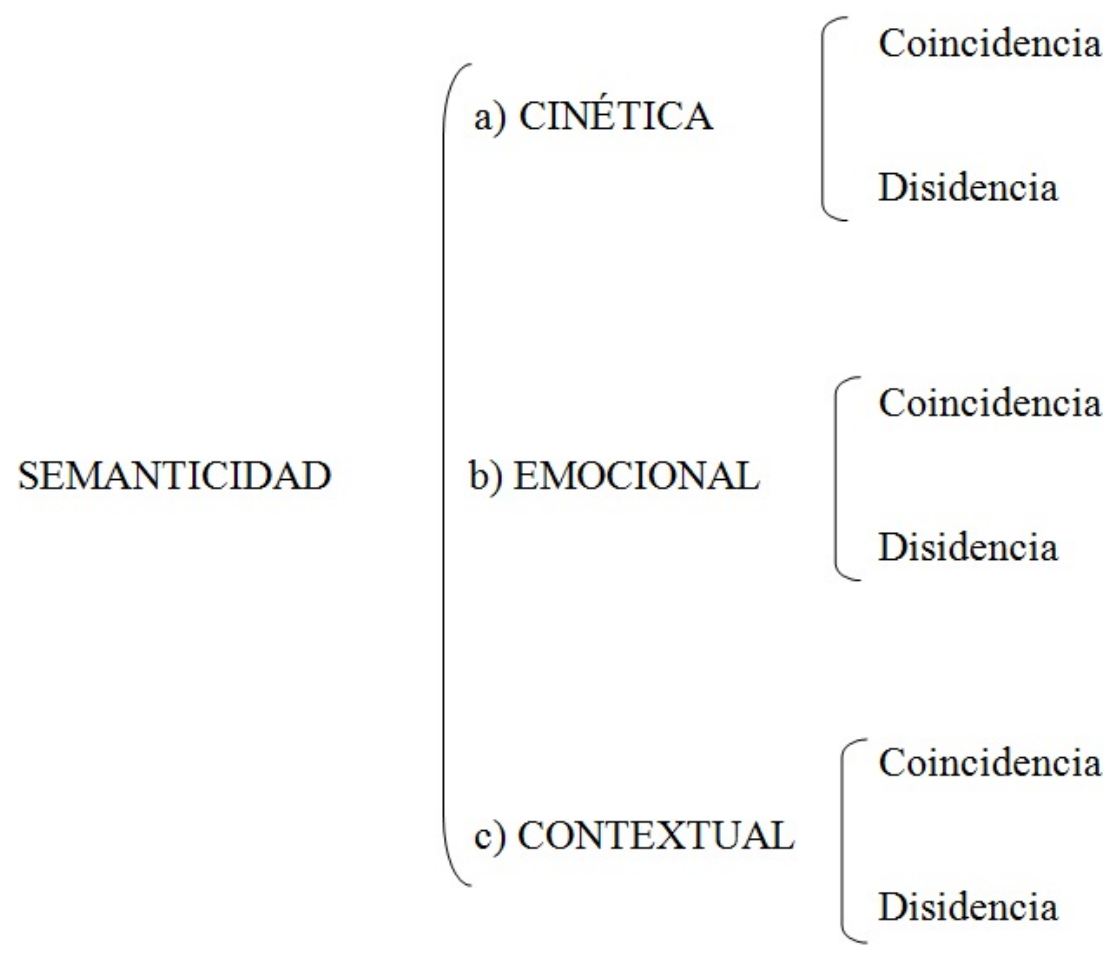

\section{A) Semanticidad cinética}

En este caso la música puede reforzar o debilitar la dinámica de la acción mediante distintos elementos: ritmo, densidad cronométrica, tempo, aceleración ralentización, etc.

Si la música reafirma el movimiento de la escena entonces estaremos ante la presencia de una coincidencia cinética (o también llamada física); por el contrario, si la música no lo hace o lo contradice estaremos ante la presencia de una disidencia cinética o física. 


\section{Coincidencia cinética}

Matrix (1999). Dirección de Lana y Lilly Wachowski; música de Don Davis

En el duelo del subte entre dos de los personajes, Neo y el Sr. Smith, la música utilizada está construida en base a la lógica de la acción y no a la lógica interna de la música. Sin embargo, no se escucha una composición caótica, sino que ella está claramente ordenada gracias a su articulación con la imagen. El fragmento musical no es demasiado definido melódicamente. Se destaca un ostinato rítmico con elementos minimalistas y una gran instrumentación orquestal. Formalmente se alternan momentos de ritmo marcado y pulsante con otros momentos sin pulso aparente, con predominio de notas largas. La alternancia depende de la acción de acuerdo a si los personajes están en movimiento o no.

Esta película ha supuesto una gran innovación tecnológica para el cine en términos de efectos visuales. Sin embargo, no debemos dejar de lado que su lenguaje cinematográfico mantiene el canon estructural clásico, y es quizas allí donde reside el logro estético tan valorado por la crítica. Se utilizan dos maneras distintas del planteamiento en torno a la acción. Por un lado, lo dramático y los efectos visuales, por el otro, el valor formal de la cámara (composición) y el montaje que hacen de lo heterogéneo algo homogéneo. La música acompaña esta escena de acción en la cual Neo y Smith luchan cuerpo a cuerpo: lo hace de manera uniforme y continua en su composición. A la vez, el suceso musical responde al acto físico. De ahí la inclusión como ejemplo para la coincidencia cinética

El empleo de la música logra su verdadero lucimiento por el campo de tensión que se establece entre la ausencia de pulso (aunque siempre esté presente la continuidad sonora) y la vuelta a la carga con ese ostinato rítmico que tiene que ver con la tenacidad de los personajes frente a lo que desean. Estas ausencias rítmicas hacen que nos metamos en la interioridad de esos cuerpos, para sentir la escena en torno a lo que significa la lucha entre el bien y el mal.

\section{Disidencia cinética ofísica}

Erase una vez en América (1984). Dirección de Sergio Leone; música de Ennio Morricone

En la secuencia del asesinato del personaje de Dominic, se aprecia una secuencia de montaje donde la música acompaña la emoción de los que estamos viendo, pero no la acción. Es una música utilizada en otros momentos del filme, de tempo lento y hondo dramatismo. La melodía es tocada por una flauta de Pan con un acompañamiento armónico e instrumentación reducida. Construye la gravedad del suceso. La utilización de la cámara lenta y el tempo musical largo establece un contraste con el vértigo de la huida del personaje en la corrida donde finalmente el niño morirá producto del disparo. De ahí la disidencia física o cinética. La música marca toda la película con un verdadero sentido de la evocación. Cada una de las secuencias a lo largo de la cinta, propondrá un ritmo parsimonioso y solemne. Se trata de solidificar el pasado con un sentido de gran melancolía. Lo que logra este tipo de operación es arrancar la propuesta genérica hacia un lugar más melodramático y a la vez autoral.

\section{B) Semanticidad emocional}

En este caso la música refuerza o debilita (incluso hasta contradice) el mundo emocional de los personajes (nostalgia, tristeza, alegría, felicidad, temor, etc.) mediante elementos tales como el carácter, la rítmica, la instrumentación, el tipo de lenguaje, etc.

Si la música lo reafirma, estaremos ante una coincidencia emocional entre ambos lenguajes. Si no es así, generará una disidencia emocional. 
Este punto se vincula en forma directa con la función expresiva de la música, que recordemos, cual contribuye a generar en la narración diversas emociones, sentimientos y sensaciones.

\section{Coincidencia emocional}

Vértigo (1958) Dirección de Alfred Hitchchok; música de Bernard Herrmann

La música que acompaña el momento en que los personajes de Scottie y Madeleine están en la habitación del hotel, es un claro ejemplo de coincidencia emocional. Sin dudas aquí se quiere dar un mensaje musical evidente: acompañar las emociones que tiene el protagonista tratando de generar con el espectador ese estado de angustia y desesperación ante la situación. La música de Herrmann acompaña a toda la secuencia acomodando su carácter e intensidad a la actuación de los actores. Suena con un estilo romántico cercano a lo wagneriano. La instrumentación es plena, orquestal, con tempos rubatos y dinámicas graduales pero exageradas, subrayando el carácter expresivo del fragmento. Su plano auditivo fuerte permite la percepción de lo sonoro en forma totalmente consciente por parte del espectador.

Desde lo visual, podemos apreciar como el montaje es de corte clásico, y acompaña con elegancia el suceso de transformación de Madeleine a pedido de Scottie.

Recordemos que la película es una tragedia que se estructura a partir de un disparador traumático. Por un lado, Scottie sufre de vértigo, y por otro, ha quedado obsesionado por la muerte de Carlota, a la cual él no ha podido salvar. La obsesión es el condicionante como línea de acción de la película. Hitchcock tiñe de polaridades el espacio con el color verde. Este no es cualquier color, sino el que los griegos utilizaban para señalar el mal. Dentro del comportamiento de los personajes en la puesta en escena, notamos como ellos se ubican en esos sectores. Esta es una de las obras emblemáticas del director, en la que más allá de su clasicismo, experimenta con respecto a sus búsquedas formales. El color es uno de esos momentos en la experimentación. Esa elección permite establecer el hecho metafísico para así bascular entre las dualidades del mundo de los vivos y los muertos.

Volviendo a lo musical, un punto importante es cuando el tema se va direccionando hasta llegar a su clímax, que coincide con el plano medio de Scottie que descubre al personaje de Madeleine convertida en Carlota, la mujer muerta. Simultáneamente, la imagen presenta efectos visuales, dando fuerza a la entrada de la música en toda su potencia expresiva, para que sintamos la emoción de Scottie. Un crescendo en intensidad y registro acompañará las acciones de los personajes, hasta que se fundan en un beso. La cámara comenzará a girar sobre ellos satelitalmente como bien ha trabajado a lo largo de todo el film. El movimiento circular es un recurrente en las formas. Cámaras con seguimiento en la primera parte de la película, el rodete de Carlota, los títulos de crédito de inicio, acompañados por el hipnótico tema musical. Esa forma geométrica circular, metaforizará el trauma del personaje.

\section{Disidencia emocional}

\section{Blade runner (1982). Dirección de Ridley Scott; música de Vangelis}

En el siguiente ejemplo, es importante señalar como desde un principio se edifica la mirada en relación al desarrollo de los personajes. A partir de allí se construye la imagen del filme, jugando en un terreno de dualidades que hace de esta película un espectáculo controversial en cuanto al contenido. Dentro de la propuesta no queda exento el valor musical.

La escena muestra al personaje principal, Rick Deckard que viene persiguiendo a Zhora (una replicant rebelde) que huye desesperadamente. Deckard comienza a dispararle con su arma. El momento es acompañado por un clima musical tranquilo, nostálgico con sonido electrónico de sintetizadores como colchón sonoro y un ruido de latidos de corazón muy suaves, pero acelerados. Los disparos se suceden uno 
tras otro, pero en forma pausada. Cuando Deckard le acierta a Zhora, el sonido ambiente prácticamente desaparece. Solo se escuchan los disparos, el ruido de los vidrios que Zhora rompe con su cuerpo y la música que está en primer plano. Se produce una disidencia emocional, una relación inversa entre la escena violenta (que pediría un momento sonoro enérgico) y una música tranquila y melancólica que muestra su melodía en modo menor evocando el timbre de una armónica electrónica.

El hecho que Deckard intente matar a una replicant rebelde debería ser algo común, ya que él es un cazador de robots. En este punto, la música cumple un rol fundamental de señalamiento e insinuación en la revelación del verdadero origen de Deckard, ya que él mismo aparentemente también es un replicant; de eso nos enteraremos al final del film. A medida que corre y dispara a esa rebelde en la misión encomendada, se observa que el gesto de él no responde a la emocionalidad del suceso. También hay un rallenti que estiliza la escena. Se comienza a revelar a partir de la construcción de la mirada de Deckard. El personaje no se siente del todo bien, y permanece reflexivo luego de cumplir con su misión. A cada rato se irán sembrando datos informativos para cosechar el carácter ambiguo de esta obra con gran tratamiento humano. Pues los humanos son un poco replicant, y los replicant un poco humanos. El sentimiento rige por sobre todas las cosas.

\section{C) Semanticidad contextual}

Por último, la música puede resaltar las características de un determinado contexto (geográfico / histórico) mediante elementos tales como la instrumentación, timbres característicos, formas musicales, danzas, canciones vinculadas a diversos géneros, etc. Nuevamente, si la música reafirma esto, estaremos ante una coincidencia contextual entre ambos lenguajes. Si no es así generará una disidencia contextual.

Este punto se vincula en forma directa con la función ambientadora de la música que recordemos, contribuye a generar en la narración, información acerca del tiempo y el espacio de lo narrado.

\section{Coincidencia contextual}

\section{Gandhi (1983). Dirección de Richard Attenborough; música de Ravi Shankar}

Tratándose de una película biográfica, es importante tener en cuenta que siempre hay investigaciones sobre los hechos verídicos que la inspiran. Es importante que esta circunstancia condicione también a todos los intervinientes para la construcción del relato. Focalizándonos en el aporte musical, éste establece en el espectador un grado de empatía en torno al contexto espacial y a la construcción de los personajes para lograr la veracidad.

En la escena del ritual funerario de Gandhi, se escucha en primer plano el sonido característico de uno de los instrumentos más utilizado en la música de la India: el sitar. Despliega una melodía típica de ese lenguaje musical tan particular, que es de la música india. Predomina la zona grave del registro, con un carácter de profundo dramatismo a la manera de una plegaría fúnebre que hace que la coincidencia contextual (en este caso geográfica) sea exacta.

Claramente se trata de lograr una atmósfera en torno a la figura de Gandhi. Ninguno de los elementos constitutivos del relato se corre un ápice para lograr el grado de creencia en torno al suceso histórico real. El mecanismo de representación de la realidad es clave para constituir no solo el espacio, sino también al tiempo que naturalmente cimenta la estructura. En este caso, se potencia la raíz socio cultural y su folklore, para entender a esa otra cultura, a partir de una situación histórica dada y constituir una trama como valor universal.

En este caso, el ingreso de relato musical nos condiciona a entender la lucha del personaje por su pueblo, y que a modo de homenaje despide las cenizas en el rio de los muertos. Asistimos al acto religioso del pueblo por su mártir. Si prestamos atención al momento de la fogata, veremos que el tratamiento visual con esa cámara 
lenta, sumado a la textura de la imagen nos remiten al género documental. Con esta decisión estética, que es acompañada con la típica música india, queda muy claro que se trata de ser fidedigno con la realidad y el mecanismo de representación. La voz en off de un Gandhi ya muerto, mitifica la lucha de éste, y hace que su legado siga viviendo en la conciencia de ese pueblo.

\section{Disidencia contextual}

2001 Odisea del espacio (1968). Dirección de Stanley Kubrick; música de Johann Strauss (hijo)

En la memorable escena en donde una nave espacial gira alrededor del planeta Tierra, el director decidió incluir un fragmento de una música preexistente que no fue compuesta para esta película. Se trata del vals $E l$ Danubio Azul compuesto en 1866 por Johann Srauss (hijo). Podemos incluirla en las llamadas músicas de concierto perteneciente al género de la música clásica o académica, compuesta para orquesta y que ha sido utilizada en todo el mundo durante décadas para ambientar las típicas fiestas de salón.

Claramente el fragmento entra en disidencia (en este caso temporo-espacial) por medio de la oposición de la música (clásica, antigua y de salón) en relación a un espacio exterior futurista (regido por lo tecnológico). Nos hace comprender el valor en el tiempo de la raza humana con relación a su conquista fundamental, el espacio. Claramente la música clásica del pasado, hace que la lógica narrativa sea retroactiva. Comprendemos a partir de un pasado que no se explicita en imagen, pero que de alguna forma la música nos activa el pensamiento. Se activa un fuera de campo fundamental para los espectadores, pues desde allí, construiremos las imágenes ausentes, con nuestra relación de saberes en la experiencia de aquello que conocemos. Desde ese lugar apreciamos la imagen como lo nuevo y lo bello. Por sobre todas las cosas, todo viaje es interior, al margen de constituir un nuevo universo en el cual el hombre puede resignificarse.

Por último, y a tener en cuenta, el punto de vista desde donde se constituye la mirada, es el hombre en el espacio, y siempre se ve el planeta Tierra desde allí.

2001 es una película estructurada claramente desde un valor muy formalista, y en este caso apreciamos como las formas geométricas son suavizadas por la música, homogeneizando el argumento del progreso como una consecuencia de orden natural en la vida de nuestra raza.

\section{3) LA MÚSICA Y SU FORMA DE ARTICULACIÓN EN LA NARRACIÓN CINEMATOGRÁFiCA RESPECTO DE LOS RECURSOS MUSICALES NARRATIVOS}

Esta categoría refiere a los distintos recursos musicales relacionados con ciertos aspectos de la narración, comparando el discurso de un fragmento musical con la línea argumental del film. El más importante de estos recursos es el llamado leitmotiv o tema central (y/o principal). Es un elemento musical, con identidad, que se construye en forma de música para dar vida a algo importante dentro del film: un personaje, una idea, un concepto, una situación, o algún otro elemento para ser individualizado y subrayado a partir de la música. Su presencia permite aportar a la narración una referencia que sirva para citar, complementar, ampliar, profundizar y hasta contradecir aquello que se quiera explicitar. La vinculación entre el tema central o leitmotiv y el elemento narrativo al que se asocia no hace necesario que todo esté explicado en el guion literario; bastará con explicar cosas que además de ser aclaratorias, aligeran la carga narrativa del guion. En general el tema central se va mostrando en el filme de acuerdo a tres procedimientos: la repetición, la variación y la transformación. En los dos primeros casos el tema mantiene el mismo significado y por la tanto son narrativamente estáticos. En el caso de la transformación la música sufre tal modificación que puede llegar a cambiar el significado inicial por lo tanto desde el punto de vista narrativo es dinámico. 


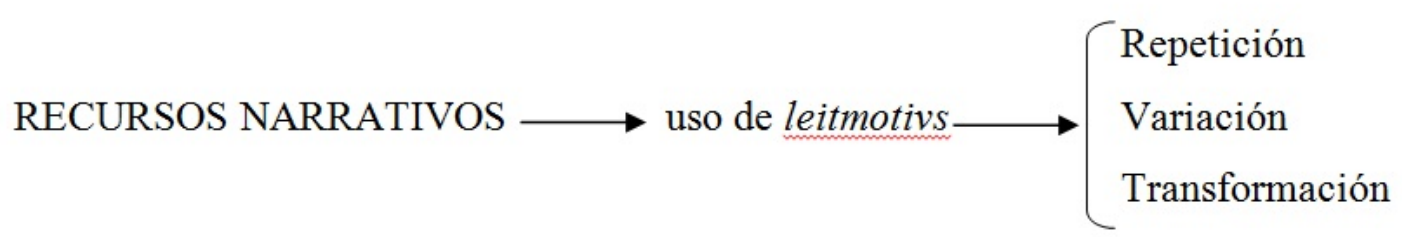

Existen también otro tipo elementos musicales útiles para la narración, como los temas secundarios, los contratemas, los subtemas, los fragmentos, los motivos etc. que si bien pueden ayudar como recursos narrativos no tienen la misma importancia que el tema central o principal.

También podemos mencionar, en un tercer nivel de importancia narrativa a ciertos procedimientos que también pueden contribuir a la narración como son la irrupción, la interrupción, el mickeymousing, etc.

Este punto está estrechamente vinculado a la típica función narrativa de la música.

La guerra de las galaxias (Episodio IV. Una nueva esperanza) (1976) Dirección de George Lucas; música de John Williams.

Varios momentos de La guerra de las galaxias, Episodio IV, son acompañados por uno de los leitmotivs principales del filme: el tema de la Fuerza. Este leitmotiv representa justamente a La Fuerza, una especie de energía presente en el universo de donde proviene toda la vida y a la que acceden los Caballeros Jedi. En el filme también representa a esos mismos caballeros Jedi e incluso individualmente a uno de ellos: Obi Wan Kenobi. Como ocurre en muchos filmes en donde la música se utiliza narrativamente, se irá repitiendo, variando y transformando su carácter, su tempo, su instrumentación, etc. para satisfacer las necesidades del relato. Esencialmente, el de la Fuerza, es un tema de tempo tranquilo con carácter nostálgico y melancólico. Es notable el uso de la escala dórica que remite a cierta sonoridad antigua lo que simbolizaría que el poder de la Fuerza es ancestral y épico. La escala dórica según algunas teorías musicales barrocas, estaba a medio camino entre la sonoridad brillante y oscura, encontrando un equilibrio sonoro. En un terreno especulativo podríamos asociar esta idea al contexto de la narración y decir que simbólicamente esta música reflejaría la búsqueda del equilibrio entre los opuestos, entre lo luminoso y lo oscuro, entre el bien y el mal.

En la primera aparición de Obi Wan Kenobi, cuando éste asiste a Luke que está inconsciente tirado en el piso en medio del desierto, se escucha un acompañamiento musical previo y el leitmotiv de la Fuerza se introduce cuando Kenobi remueve su capucha y descubre su rostro. Esta aparición del tema, toma aquí un carácter dramático con la instrumentación predominando en el registro medio grave respondiendo al misterio planteado por la trama, ya que aún no conocemos las intenciones de este nuevo personaje. La melodía que se escucha es la cabeza del tema tocada por el corno francés, sostenida por un pedal grave en las cuerdas. De esta forma, la entrada musical nos ubica en el lugar de conocimiento del protagonista reforzando el punto de vista establecido en la narración, así como asigna valor a la aparición de un nuevo personaje que será importante en la trama. A continuación, el leitmotiv es utilizado una segunda vez en el fragmento, pero de forma distinta cuando Obi Wan asume su identidad. Esta vez la instrumentación mantiene su presencia sutil y se presenta de manera más cristalina alejándose del misterio y la peligrosidad que poseía momentos atrás. La melodía es tocada por un oboe. Esta variante en la instrumentación refuerza el vínculo que establece el diálogo entre los personajes. El misterio da paso a la confianza a medida que Obi Wan recuerda el tiempo pasado. En este punto ya no sólo se asocia el leitmotiv al personaje de Obi Wan, sino a un pasado y a un tiempo lejano que emerge a través de la palabra de Kenobi, que es reforzado narrativamente a través del carácter melancólico de la melodía.

En la secuencia siguiente, Luke, está intentando reparar a su droide, mientras dialoga con Obi Wan. El leitmotiv, se utiliza en dos momentos puntuales marcados por la mención de la Fuerza, alternándose con otros temas que se van acoplando a las necesidades narrativas. Se escucha por primera vez cuando Obi Wan da a Luke una introducción a la filosofía de la Fuerza. Nuevamente el carácter melancólico de la melodía encuentra 
su anclaje en las palabras de Kenobi que evocan un pasado de luminosidad y civilización y a su vez introduce el elemento mágico que representa el poder de los Jedi. La instrumentación y el carácter son muy similares al de la primera aparición por lo que podemos decir que se le aplica el recurso de la repetición y por lo tanto el significado musical no varía demasiado siendo estable desde lo narrativo. El leitmotiv es utilizado por segunda vez cuando Obi Wan, luego de pedir la ayuda de Luke, le insiste para que aprenda a utilizar la Fuerza. Esta vez aparece con su melodía duplicada por un intervalo de $8^{\circ}$ en las maderas y una instrumentación más brillante. La utilización de la música no sólo refuerza el vínculo entre el leitmotiv y el concepto de Fuerza sino que participa en un momento clave en el camino del héroe. En El héroede las mil caras, Joseph Campbell reconoce distintos estadios en los pilares que constituyen en múltiples culturas y leyendas populares la formación de la figura del héroe. Es posible trazar paralelismos entre esos pasos en la constitución de un género épico. La saga de La guerra de las galaxias no está exenta de ser vista a la luz de este estudio. Tal como vemos en el fragmento, la aparición del mentor, el llamado a la aventura y el inicio del camino hacia el mundo mágico forman parte de esos estadios y el leitmotiv aparece para destacarlos, acuñando los pilares narrativos del género épico. De esta manera el tema que en un comienzo asociamos al personaje de Obi Wan y a un pasado perdido teñido por la melancolía, ahora encuentra su anclaje en un elemento mágico: la Fuerza. Existe una razón narrativa en que a lo largo de toda la saga el concepto de la Fuerza y Obi Wan Kenobi compartan el mismo leitmotiv. En un principio, Obi Wan es para Luke el único representante de los Jedi y las enseñanzas de la Fuerza. Cumple el rol para Luke de un mentor de lo desconocido. Pero a lo largo de toda la saga Obi Wan también será siempre el arquetipo de Caballero Jedi y poseerá el cúmulo de todas sus virtudes en el dominio de la Fuerza, es por eso que el leitmotiv funciona en ambos sentidos.

En otro momento del filme, el tema de la Fuerza vuelve a tener dos apariciones con diferentes transformaciones que responden a la transición emocional que realiza el personaje de Luke en la escena. En un primer momento el leitmotiv acompaña a Luke en la urgencia del peligro que pesa sobre su hogar y sus tíos. Aquí la melodía se presenta tocada por los metales, con un tempo acelerado. Lejos del tono melodioso y melancólico, se asemeja más a la forma de marcha que tendrá en el final de la película. Esto encuentra su origen en la caracterización del personaje de Luke, que luego de la advertencia de peligro de Obi Wan se apura en ir al rescate de sus tíos, mostrando su carácter heroico y valeroso. El tema de la Fuerza en este momento muestra la misma intención, acompañando al personaje en su resolución de lucha frente a la amenaza. La segunda aparición del leitmotiv es luego del conocimiento de la muerte de sus tíos. Esto será un punto de inflexión en el relato, ya que este descubrimiento será lo que empuje al personaje a la aventura y lo motivará a acompañar a Obi Wan. Luego de un clima musical previo, el tema de la Fuerza vuelve a escucharse con un carácter mucho más dramático con la melodía tocada por los violonchellos lo que acentúa la gravedad de la situación. El leitmotiv de la Fuerza en este momento de quiebre indica el destino que deberá seguir el héroe para encontrar justicia frente el hecho, se presenta como una respuesta y una luz luego de perderlo todo. Es interesante advertir una leve variación sobre el final, ya que la melodía incorpora un rasgo de oscuridad en el momento en que Luke realiza un leve gesto de enojo. Esta operación presenta un conflicto que acompañará al personaje durante toda la saga entre la venganza y la justicia. El conflicto entre el lado "luminoso" y "oscuro" de la fuerza, incipiente pero reconocible en este punto, ganará en la progresión de la película y la saga una mayor importancia, tanto en lo dramático como en lo musical.

En el acontecimiento del duelo entre Dark Vader y Kenobi, en el cual éste último morirá, la utilización del leitmotiv de la Fuerza tiene como función narrativa sugerir en concordancia con la desaparición, el carácter mágico de su partida. En la trama, la muerte de Obi Wan es en realidad la fusión de él mismo en la Fuerza, es conseguir la trascendencia luego del cumplimiento de su destino y su tarea. La presencia del leitmotiv en ese momento construye el sentido trascendental del acto, del sacrificio del mentor de Luke como punto de partida para que se consolide como un nuevo héroe. Acompañando la acción, el tema de la Fuerza, se escucha brevemente (solo su primer motivo), pero a pesar de ello se percibe transparente ya que ingresa con gran contundencia con su melodía tocada por el corno francés. 
Por último, en el final del filme, existe una celebración catártica por el logro obtenido. Luke se consolida como héroe luego de realizar una hazaña gracias al uso de la Fuerza y su capacidad para dominarla. El leitmotiv aparece aquí totalmente transformado. La instrumentación es plena, un tutti orquestal con predominio de los metales en la melodía a la manera de una fanfarria y los timbales haciendo contratiempos. Es un final a toda orquesta tocando en el fortísimo emulando a una marcha triunfal. Si anteriormente el leitmotiv fue presentado con cierta melancolía por un pasado perdido, aquí toma la dimensión de un presente de lucha y la conformación de una rebelión futura. Los planos generales que dejan ver el ejército rebelde completan el sentido. La fuerza y el héroe han renacido y con ellos la posibilidad de enfrentar al Imperio.

\section{REFERENCIAS}

Adorno, T. y Eisler, J. (1976). El cine y la música. Madrid: Fundamentos.

Amiel, V. (2001). Estética del montaje. Madrid: Abada.

Aumont, J. (2010). El cine y la puesta en escena. Buenos Aires: Colihue.

Bonitzer, P. (2007). Desencuadres. Cine y pintura. Buenos Aires: Santiago Arcos.

Bonitzer, P. (2007). El campo ciego. Ensayos sobre el realismo en el cine. Buenos Aires: Santiago Arcos.

Bordwell, D. (2013). El significado del film. Barcelona: Paidós.

Bordwell, D. y Thompson, C. (1995). El arte cinematográfico. Barcelona: Paidós.

Burch, N. (1970). Praxis del cine. Madrid: Fundamentos.

Chion, M. (1993). La Audiovisión. Barcelona: Paidós.

Chion, M. (1995). La música en el cine. Barcelona: Paidós.

Cassetti, F. y Di Chio F. (2007). Como analizar un film. Barcelona: Paidós.

Cuellar, C. (1998). Cine y música. El arte al servicio del arte. Valencia: Universidad Politécnica de Valencia, Servicio de Publicaciones.

De Arcos, M. (2006). Experimentalismo en la música cinematográfica. Madrid: Fondo de cultura económica.

Delleuze, G. (2009). La imagen-movimiento. Buenos Aires: Paidós.

Delleuze, G. (2011). Cine II, Los signos del movimiento y el tiempo. Buenos Aires: Cactus.

Gaudreault, A. y Jost, F. (1995). El relato cinematográfico. Barcelona: Paidós.

Mercado, G. (2011). La visión del cineasta. Salamanca: Anaya.

Morricone, E. y De Rosa, A. (2016). En busca de aquel sonido. Barcelona: Malpaso.

Nieto, J. (1996). Música para la imagen. La influencia secreta. Madrid: SGAE.

Padrol, J. (1988). Cine y música. Barcelona: Salvat.

Randel, D. (1986). Diccionario Harvard de la Música. España: Alianza.

Rodríguez Fraile, J. (2001). Ennio Morricone. Música, Cine e Historia. Badajoz: Diputación de Badajoz.

Rowell, L. (1985). Introducción a la filosofía de la música. Barcelona: Gedisa.

Rohmer, E. (2005). De Mozart en Beethoven. Madrid: Ardora.

Villain, D. (1997). El encuadre cinematográfico. Barcelona: Paidós.

Xalabarder, C. (1997). Enciclopedia de las bandas sonoras. Barcelona: Ediciones B.

Xalabarder, C. (2005). El guión musical en el cine. Barcelona: Conrado Xalabarder.

Xalabarder, C. (2013). Música de cine: una ilusión óptica. Barcelona: Conrado Xalabarder.

Zunzunegui, S. (1996). La mirada cercana. Barcelona: Paidós.

CC BY-NC-SA 